\title{
Identifying Educator Related Variables on Grade 6 Learner Achievement in the Mathematics Annual National Assessment (ANA) Results in South Africa
}

\author{
Wendy N. Setlalentoa* \\ Faculty of Humanities, Department of Mathematics, Science and Technology Education, Central University of Technology, \\ Free State, Private Bag X20539, Bloemfontein 9300, South Africa \\ wsetlale@cut.ac.za
}

\section{Doi:10.5901/ajis.2015.v4n1p407}

\section{Abstract}

Every educator has an ability to implicitly and explicitly influence the learners' education. This study explored how the Grade 6 learner achievement in Mathematics Annual National Assessment (ANA) link with the educator's inputs (teaching experience, academic qualifications and subject specialisation). Educators from ten (10) Primary Schools in the Motheo Education District of Free State Province of South Africa constituted the target population for this study. 49 Grade 6 mathematics educators participated in this study. Questionnaires were used to collect data. Multiple regressions were used to analyse data. The study found that there was a significant relationship between the educator inputs and learner achievement. The gender of participants was however found not significantly related to learner achievement. It is anticipated that this study will assist the Department of Education as it provides the basis for subject specialisation, teaching experience to employment allocation.

Keywords: Annual National Assessment (ANA), learner performance, mathematics performance, educator qualifications, teaching experience

\section{Introduction}

International and national studies and trends show that South African learners are lagging behind in terms of their mathematics skills as compared to other countries (Howie, 2001; 2004; Reddy, 2006). The results and performance of Grade 8 and Grade 9 in the Trends in International Mathematics and Science Study (TIMMS) of 1999, 2003 and 2011 the largest international study of mathematics and science achievement ever undertaken. Howie $(2001 ; 2004)$ and Reddy (2006) also revealed that South African learners had the lowest scores amongst 42 countries. Although the performance in TIMMS 2011 show some improvement and progress in the standard of Mathematics, South Africa still scored below the performance benchmark, and ranked amongst the six lowest countries that participated in the assessment (Human Sciences Research Council [HSRC], 2012). The concern regarding this state of affairs revolves around one primary factor: education quality (Howie, 2004).

\section{Context of Study}

The education system in South Africa comprises the Reception class Grade R, Foundation Phase, that is Grades 1-3, The Intermediate Phase Grades 4-6, the Senior Phase, Grades 7-9 and the Further Education \& Training (FET) Phase Grades 10-12. The focus of the study was on learner achievement in mathematics at the exit level of the intermediate Phase (Grade 6) in the Annual National Assessments (ANA) in the years 2011-2013 in the Motheo Education District, Free State Province.

\section{Purpose of ANA}

Improving the quality of basic education is the core mandate of the Department of Basic Education. ANA is a diagnostic tool used to identify weaknesses and inform interventions for the improvement of literacy and numeracy and an assessment tool supporting, Action Plan to 2014, Towards the Realisation of Schooling 2025.

ANA presents opportunities to reflect on what has been achieved, lessons to be learnt and challenges that still need to be tackled towards achieving the goals specified in the official document titled Action Plan to 2014: Towards the Realisation of Schooling 2025. 


\subsection{Development of tests}

Panels of teachers, subject and assessment specialists selected across the country develop the tests for Languages and Mathematics according to Specification Frameworks.

Quality assurance processes include review of tests by internal moderators, a pilot study, refinement, editing and inputs by external experts.

A total of 92 versioned tests are administered to cover the subjects (Mathematics and Languages), grades and also adaptations for learners with barriers to learning which included the partially-sighted, blind and deaf.

Studies conducted by the Human Sciences Research Council (HSRC) indicate that the achievement scores in mathematics and science in South Africa are very low compared to other participating countries. This alarming state of mathematics and science education in South Africa was also revealed by the TIMSS of 2011.

A summary of the key findings in the ANA Diagnostic Report of 2012 identified the following areas of weakness in mathematics: Learners were unable to apply their knowledge and mathematical principles to solve word problems, they could not apply their knowledge of fractions and percentages in given contexts, and they also struggled when working with more than one concept in a question (Department of Basic Education, 2013). Other areas of weakness were also identified, which pointed to learners' lack of problem solving skills that are crucial and essential for learning mathematics effectively. Moreover, evidence showed that learners were unable to construct their own answers to questions asked. over the past three years the average percentage pass in mathematics ANA in the Motheo Education District, has been below 50\% (see Table 1 below).

Table 1: Motheo District Performance in Grade 6 Mathematics ANA 2011-2013

\begin{tabular}{|c|c|c|c|}
\hline District & $\mathbf{2 0 1 1}$ & $\mathbf{2 0 1 2}$ & $\mathbf{2 0 1 3}$ \\
\hline & Average \% mark & Average \% mark & Average \% mark \\
\hline Motheo & 28 & 27.8 & 40.3 \\
\hline
\end{tabular}

(Statistics adapted from ANA Reports 2011-2013 respectively)

\section{Objective of the Study}

Given the magnitude and gravity of the poor performance in the ANA, it is imperative for specifically identified contributory factors and in particular the effects of teacher-related variables on students' achievement, to be examined empirically. It is this context that provided impetus to the present study. The study therefore, sought to explore how various aspects of educator quality inputs: classroom practices and professional development influence each other and how these myriad influences impacted on learners' ANA results

\section{Research Question}

To what extent did the following educator qualifications, field of specialisation, and years of experience affect learner academic performance with regard to performance in the ANA, specifically in mathematics?

\section{Research Methodology}

The quantitative research methodology was used. Structured questionnaires were used to collect data from 49 educators. Multiple regressions were used to analyse data.

\subsection{Participants and setting}

Convenient sampling of 10 Primary Schools in Motheo Education District selected constituted the target population for this study. Participants in this study were 49 Grade 6 mathematics educators.

A self-administered questionnaire was distributed to 49 educators at the targeted primary schools to determine the link between the educator's relative variables and the learner's academic achievement in Grade 6 ANA mathematics.

\subsection{Reliability and Validity of Instruments}

The items in the questionnaires were crafted such that they revealed a link between the educator's relative variables and the learner's academic achievement in mathematics. These items were selected because they were reported to have a 
relationship with learner's academic achievement in mathematics in previous studies (Darling-Hammond, 2000). The reliability for the measure with this study sample was found to be 0.76 , calculated using Cronbach Alpha.

\subsection{Data collection}

The Grade 6 learner's ANA results in mathematics (2011- 2013) were obtained from the ANA reports of 2011-2013. Information regarding educator inputs (educational qualifications, teaching experience), was obtained through the selfadministered questionnaires. The dependent variable was the average score of selected schools in ANA mathematics results in the years 2011 to 2013.

\subsection{Data Analysis}

Data were analysed using both descriptive and inferential statistics.

First, descriptive statistics were used to explain the educator's biographic characteristics by gender, subject specialisation, teaching experience, academic and professional qualifications.

Thereafter a correlation analysis was done to identify the extent of the relationship between the learner's achievement and the independent variables (educator inputs). In the last stage, a standard multi regression analysis was used to test the relationship between the educator inputs and the learner's ANA mathematics academic achievement in the 10 sampled schools. The output of the standard multiple regression analysis helped to shed light on how the variables that significantly affect the learner's academic gains and performance in ANA mathematics as identified could predict the learner's achievement.

Standard Multiple Regression Assumption Analysis

Keith (2006) contends that Multiple Regression (MR) is the most significant because it directly relates to the bias of results for the entire analysis.

\section{Results and Discussions Based on the Standard Multiple Regression Analysis (SMRA)}

Table 2: Summary of educator's inputs (teaching experience, subject specialization, academic achievement and gender) on learner's academic achievement in Grade 6 ANA mathematics.

\begin{tabular}{c|c|c|c|c}
\hline $\mathrm{R}$ & $\mathrm{R}$ Squared & Square Adjusted R Standard Error of & $\mathrm{F}$ & $\mathrm{P}$ \\
\hline .38 & 0.15 & .0 .18 & 6.38 & .042 \\
\hline
\end{tabular}

Table 2 reveals that the educator inputs made a contribution of 15.9\% on the learner's academic achievement in Grade 6 ANA mathematics. It implies that $84.1 \%$ unexplained factors that influenced learner's Grade 6 ANA mathematics results are beyond the educator's teaching experience, subject specialization, academic achievement and gender. The F-value (6.38) which is significant at $0.05(P<0.05)$ reveals that the joint effects of the educator's inputs on learners academic achievement in Grade 6 ANA mathematics is significant.

Table 3: The Parameter Estimates of the educator's Inputs on the learner's Academic Achievement in Grade 6 ANA mathematics

\begin{tabular}{|c|c|c|c|c|c|}
\hline \multirow{2}{*}{ Model } & \multicolumn{2}{|c|}{ Unstandardized Coefficients } & \multicolumn{2}{|c|}{ Standardized Coefficients } & \multirow[b]{2}{*}{$p$} \\
\hline & $\beta$ & Std. Error & Beta & $\mathrm{t}$ & \\
\hline Constant & 0.56 & .10 & & 5.51 & $0.000 * * *$ \\
\hline Teaching experience & 0.38 & 0.16 & 0.19 & 2.43 & $0.04^{*}$ \\
\hline Academic Qualifications & .59 & 0.15 & 0.37 & 3.93 & $0.09 * *$ \\
\hline Subject specialisation & 0.47 & 0.17 & 0.47 & 2.81 & $0.05^{\star}$ \\
\hline Gender & 0.03 & .02 & 0.33 & 1.50 & 0.51 \\
\hline All constructs & 0.41 & 0.13 & 0.46 & 3.08 & $0.03^{*}$ \\
\hline
\end{tabular}

Significant at $P<0.05 ; \mathrm{t}(149 ; 0.025)=1.976$

Table 3 above depicts the relative contribution of each educator's input variable on learner's academic achievement in grade 6 ANA mathematics. The educator's teaching experience $(\boldsymbol{\beta}=0.38 ; t=2.43 ; P<0.05)$, academic qualifications $(\boldsymbol{\beta}=.59 ; \mathrm{t}=3.93 ; \mathrm{P}<0.10)$, and subject specialisation $(\boldsymbol{\beta}=.47 ; \mathrm{t}=2.81 ; \mathrm{P}<0.05)$, had a significant positive relationship on 
the learner's academic in grade 6 ANA mathematics. The educator's gender had a negative relationship with the learner's academic achievement in grade 6 ANA mathematics. The beta values of the model revealed that the educator's academic qualifications contributed most (59\%) to the learner's academic achievement, followed by subject specialisation $(47 \%)$ and teaching experience (38\%) in order of rank.

\section{Discussions of the Findings}

The study investigated the extent to which the educator's teaching experience, academic qualification, subject specialization and gender influence learner academic achievement in ANA mathematics.

The findings of this study confirmed that educator experience, academic qualification, and subject specialisation had a moderate positive and significant relationship with learner achievement in ANA mathematics achievement? The findings of this study concur with the findings of Adeyemi (2010), and Yala and Wanjohi (2011), that teachers' teaching experience and academic qualifications were most important predictors of students' academic achievement.

The study also revealed that educator gender did not have a significant effect on the learner academic achievement in the ANA mathematics. These findings correspond with those of Akiri and Ugborugbo (2008), who found that there was no significant relationship between teachers' gender and students' academic achievement.

Regarding the educator's teaching experience, the findings of this study concur with those of Goe (2007), Kane, Rockoff and Staiger (2006) and Darling-Hammond (2000) in that the educators (teachers) teaching experience has a significant positive influence on the learner's (student's) achievement in mathematics within the first four or five years. These results however, cannot be interpreted to mean that in general the most highly experienced educators are significantly more effective than educators with limited experience.

\section{Conclusion}

The study found that there was a significant relationship between the educator inputs with learner achievement. The educator's gender was however found not significantly related to the learner achievement in mathematics. These are significant findings that have not previously been empirically demonstrated in the context of South Africa. Further research is needed to confirm the findings.

As a result of a positive and significant relationship that has been demonstrated between educator variables and learner achievement, the findings from this study may be of benefit to policymakers, the Department of Education and researchers who may want to implement effective teacher-education programmes that target the improvement of the identified teacher variables as it provides the basis for subject specialisation, teaching experience to employment allocation.

Education should mirror a car assembly line, for example, the final touches are not effected by robots, each car is different, but fuelled by the same quality; each assembler is a role model - prepared, consistently meticulous, multiskilled, uses support, but accountable, adds value in limited contact time, and continuously punctual, because the assembled cars are also the incentives for assemblers.

\section{References}

Adeyemi, B. 2010. Teacher's Related Factors as Correlates of Pupils Achievement in Social Studies in South West Nigeria. Electronic Journal of Research in Educational psychology, 8(1): 313-332.

Akiri, A.A. and Ugborugbo, N. M. 2008. An Examination of gender Influences on Teachers' Productivity in Secondary Schools. Journal of Social Sciences, 17(3): 185-191.

Darling-Hammond, L. 2000.Teacher quality and student achievement: A review of state policy evidence. Education Policy Analysis Archives, 8 (1), 50.

Department of Basic Education, 2013. Diagnostic Report - Annual National Assessmet 2011, 2012.

Department of Basic Education, 2013. Diagnostic Report - Annual National Assessmet 2012, 2013. South Africa.

Howie, S. 2001. Mathematics and Science Performance in Grade 8 in South Africa 1998/1999. Pretoria: HSRC Press.

Howie, S. 2004. A national assessment in mathematics within an international comparative assessment. Perspectives in Education, 22:149-162.

Human Sciences Research Council (HSRC). Highlights from TIMSS 2011 - 2012. The South African perspective,

Kane,T.J, Rockoff, J.E, and Staiger, D.O. 2006. What does certification tell us about teacher Effectiveness? Evidence from New York City (NBER working Paper No.W12155). Cambridge, MA: National Bureau of Economic Research.

Keith, T. 2006. Multiple regression and beyond. PEARSON Allyn and Bacon

Reddy, V. 2006. Mathematics and Science Achievement at South African Schools in TIMSS 2003. Cape Town: Human Sciences Research Council.

Yala, P. O.and Wanjohi, W.C. 2011. Performance determinants of Kenya Certificate of Secondary Education in Mathematics in secondary schools in Nyamira Division, Kenya. Asian Social Science, 7(20): 107-112. 